\title{
How the Educated Unemployed Youth in Ghana and Sri Lanka Use their Time
}

\section{Kwasi Boakye}

Among the problems facing developing countries is that of how to cope with a situation in which many of their citizens aged 15 to 24 , who have left school with at least 10 years of education, are openly, and for most of the year, without any regular wage/salary or self employment, despite their efforts at job-seeking. One approach to the problem is to explore how such youth use their time and why, and whether policy options might be deduced from the findings. This paper will take such an approach, basing the discussion on the results of two pieces of research on 'Job Seekers and Job Placement Services' sponsored by the Commonwealth Secretariat Youth Programme and carried out in Sri Lanka in 1975 and Ghana in 1976 [Dore et al 1975, Boakye forthcoming, Oxenham forthcoming]. We present first some background on the problem of educated unemployment in the two countries.

\section{Ghana and Sri Lanka in Perspective}

Despite differences in their geography and social structure, Ghana and Sri Lanka broadly share some of the variables with which we are concerned. As a result of their exposure to British rule and influence for more than a century, both countries have a long history of Western education in its 'traditional' structure (rigid timetabling, 'grammar' curriculum, promotion based on academic attainment, and examination success as the be all and end all of schooling), and function (book knowledge for occupational selection and promotion for lucrative white collar employment). Economically, agriculture remains the most important occupation and the greatest source of foreign exchange, yet in both countries the proportion of youth in this area of activity is relatively small. In Ghana as well as Sri Lanka, the requirement of academic qualifications for high level salary work with fringe benefits, still persists, and it is believed that most job seekers and their parents are aware of this. Over a considerable period, the absorptive capacity of their modern sectors has been weak. Yet population growth in both countries is higher than 2 per cent per annum and younger school leavers with higher academic qualifications (than their predecessors a decade before) are increasing.

\section{The Extent of Educated Youth Unemploy- ment in Ghana and Sri Lanka}

The exact numbers of educated youth who are unemployed in the two countries are not known but can be estimated from official statements. The ILO Employment Mission to Sri Lanka expressed the situation in these words:

Among those who are young and educated, the figures [unemployment] are particularly high. Among young people aged 15-24 with ' $O$ ' level passes, the rate of open unemployment is no less than 70 per cent...

[ILO 1971: 38]

In similar tone, the Government of Ghana recognises that among the manpower problems facing the country is that of

growing unemployment, particularly in the urban areas and largely among the age group between 15 and 24, and the widening discrepancy between certain categories of products of an educational institution on the one hand and job opportunities on the other.

[Ghana 1977, Part II: 377]

The governments are concerned because the numbers keep increasing, but also because the existence of jobless educated youth in itself reflects a high social and economic cost: it increases the imbalances in income distribution; it stimulates migration from the rural to the urban areas, and too great an influx strains services in the cities whilst depriving the rural areas of the human potential for development; and it imposes long waiting periods which cause frustration to individuals, their families and even society as a whole, as happened in the youth insurrection in Sri Lanka in 1971.

\section{The Research Methodology}

Discursive, conversational house-to-house interviews were conducted with school leavers in eight communities in Southern Ghana and six in Sri Lanka on a range of issues including: what they were currently doing; if they were already earning some form of livelihood, how they came by it and how it matched up to their expectations; if they were looking for employment, what kind they were willing to settle for, and how they went about seeking it; and what use they made of employment agencies. The evidence presented 
here is based on the responses of 238 and 91 unemployed youths in Ghana and Sri Lanka respectively. All the Ghanaians (156 males and 82 females) had completed 10 years of schooling and had obtained the Middle School Leaving Certificate. They are part of a relatively large pool of young people. The Sri Lankans ( 31 males and 60 females) had at least 10 years of schooling and graduated with at least five GCE ' $O$ ' level passes. They form part of a relatively small group of high achievers who nevertheless have difficulty over employment.

\section{How the Educated Unemployed Use their Time}

As might be expected, and in contrast to the former régime in school, or the employment market which they seek to enter, there is no rigid pattern in the way the educated unemployed youth in Ghana and Sri Lanka use their time. This does not imply that they do nothing. On the contrary, they are involved in many activities aimed at improving themselves or at least maintaining their economic existence. The salient feature of such activities is that the time allocated is less structured and more responsive to ad hoc demands and opportunities. Of the various ways in which our youth used their time, three are discussed below (job seeking, helping the family and casual labour), and their implications for development policy considered.

\section{Job Seeking}

Unsurprisingly, the most important activity with which the educated unemployed youth are preoccupied is job seeking-important not necessarily in terms of the amount of time allocated to it, or even in terms of the degree of intensity. (In fact, in both countries 'searching for jobs actively' took less than 25 per cent of the job seekers' time, and as Mook states, the unemployed 'show a very low intensity of actual job seeking' [Mook nd].) But it is important for economic independence and even survival. Firstly, most adolescents are expected to start managing their own affairs, including earning a livelihood and so dependence upon parents and other relatives is expected to decrease. Secondly, Ghana and Sri Lanka do not provide unemployment benefits to their citizens, and periods of unemployment may range from three months to three years or more after school. Thirdly, both countries have had a rather disproportionately high share of the inflation which is world-wide, and even salaried, and, to some extent, self employed workers, find it difficult to make ends meet. The unemployed are thus in a squeeze and simply must find ways of keeping body and soul together.

What kind of jobs do the educated unemployed seek? The impression that most educated youth in developing countries are unemployed because they seek non-existent white collar jobs is widespread. We hear that the kind of education they have received makes them reject other forms of work, especially those considered to be 'blue collar' or manual. In a recent study, the Manpower Division of the Government of Ghana gave as one of the reasons for youth unemployment that:

the prevailing system of 'colonial' education has ... fostered among Polytechnic graduates unrealistic attitudes, expectations and aspirations. Most of the graduates prefer to go in for white collar jobs, and are reluctant to soil their hands with manual work.

[Ghana 1975: 72]

A similar attitude is reported in Sri Lanka too. The ILO Mission stated that 'Ceylon's labour market reveals two types of imbalance', one of which is 'a structural imbalance, in which the type of work which people are willing and able to do does not match the pattern of opportunities available' [ILO 1971:234], and mentioned that there were vacancies in unpopular jobs, such as toddy tapping, for which Ceylon had turned to India as a source of labour (p 26).

But our respondents were not expecting a red carpet reception and treatment in their jobs. To the question 'when deciding if a job is suitable, what things do you have in mind?', there were realistic answers. They thought it was a benefit to have a job which yielded high income without too much exertion of human energy; for a salary or wage-earning job there might be adequate conditions of service, such as housing, health and transport facilities, plus assurance of pension and gratuity at old age. But they did not expect, in their present circumstances, to come anywhere near obtaining such jobs. As Foster put it, referring to secondary school pupils:

students are at their most realistic . . . in assessing the kind of jobs that will be available to them with a given level of education. Their expectations are relatively limited and few expect to obtain more than 'middle level' jobs. One can only expect that there is a downward trend in expectations, and the secondary school pupil no longer enjoys the kinds of opportunities which were available to him a few years ago.

[Foster 1965: 289] 
The operational question was posed as follows: 'with your present educational background and age you may not obtain what you want or desire; what do you in fact expect to do or think you are likely to get?' Their answers are broadly categorised in Table 1. them to be modest, especially as the Government of Sri Lanka, then headed by a woman, gave priority to men in allocating its jobs. The high proportion of 'undecided' females in Sri Lanka suggests that many have given up hope of salaried employment, but have not quite resigned them-

Table 1

Broad categories of jobs being sought by educated unemployed youth in Ghana and Sri Lanka (\%)

\begin{tabular}{lcccccc}
\hline \multirow{2}{*}{$\begin{array}{l}\text { broad category of job } \\
\text { being sought }\end{array}$} & \multicolumn{3}{c}{ country } \\
\cline { 2 - 7 } & male & $\begin{array}{c}\text { Sri Lanka } \\
\text { fiemale }\end{array}$ & all & male & $\begin{array}{c}\text { Ghana } \\
\text { female }\end{array}$ & all \\
\hline Salary/wage & 78 & 32 & 55 & 52 & 65 & 58 \\
Self/apprenticeship & 17 & 39 & 28 & 43 & 35 & 39 \\
Undecided & 5 & 29 & 17 & 5 & 0 & 3 \\
Total & 100 & 100 & 100 & 100 & 100 & 100 \\
& $\mathrm{n}$ & $(60)$ & $(91)$ & $(156)$ & $(82)$ & $(238)$ \\
\hline
\end{tabular}

There are clear differences between the young men and women of the two countries. That a much higher proportion of Ceylonese males should expect salaried employment seems surprising, in view of the long history of educated unemployment in their country, but they know that most of their kind have in the past been successful in getting salaried employment eventually. The much higher proportion of Ghanaian males willing to settle for apprenticeship or self employment is not surprising, in view of the social esteem for the successful self employed. Also, it must be noted that, of the Ghanaians who did expect salaried employment despite current unemployment, 80 per cent said that they would use savings from their salaries to set themselves up in their own businesses. No such declaration was forthcoming from the Ceylonese. Amongst the young women of both countries, very similar proportions have reconciled themselves to self employment. With Ghana's tradition of women in independent businesses and livelihoods, there might well have been an expectation of a proportion more closely matching or even exceeding that of the Ghanaian men. However, women with 10 years of schooling are still a comparative minority, so that expectations of salaried employment may persist. The striking difference between the women of the two countries lies in the proportions still expecting salaried employment and undecided. Half as many Ceylonese women as Ghanaian continue to expect salaried employment. Perhaps the experiences of their fathers and brothers have taught selves to self employment. Again, the echo of a possible aversion to self employment in Sri Lanka suggests that measures proposed for that country will need to differ from those of Ghana.

\section{Tactics in Job Searching}

The tactics adopted by our educated unemployed in their search for jobs were varied and complex. For there were combinations and permutations of approaches which each individual searcher followed; and attempts to categorise them are difficult. This is compounded by other factors such as the sources of information about actual or perceived vacancies and the role of relatives in the job search. Perhaps the process may best be described as a range of possibilities within which the various factors and strategies interplay. From the responses, two main approaches can be identified-official (through the writing of application letters and applying through the labour exchange), and unofficial (mainly through personal contacts); these might be used by the individual, and/or his relatives. For example, making an official approach, an individual might see an advertisement in the newspaper, or, in the case of Sri Lanka, the Government Gazette, ${ }^{1}$ write a formal application and wait hopefully. Around 27 per cent of all the respondents in Ghana, and a similar proportion of boys in Sri Lanka ( 2 per cent among the girls) were in this category. In three out of four cases there will be

\footnotetext{
1 In Sri Lanka a Computer Scheme was introduced in 1970 to process recruitment into clerical ranks but only five per cent of the respondents used it.
} 
no reply at all; in about 20 per cent of the cases he will receive a letter of regret; and, in about 5 per cent of the cases he may be called for an interview but usually the result is another rejection.

Using the semi-official approach, the applicant follows up his letter of application by personal contacts through junior and senior officers in the department concerned, or by going to the Employment Centre to 'wait for his luck'. The unofficial approach is where purely personal contacts are made with those who can influence the applicant's recruitment. In Ghana almost 70 per cent of the respondents used both the official and unofficial approaches; in Sri Lanka, a similar proportion of the boys mentioned 'politics' (ie personal contact) as very influential in recruitment.

The individual-cum-relatives approach or the relatives only approach are less formal and depend more on lobbying than on formal applications, though in both countries, the British bureaucratic heritage insists that formal applications have to be lodged.

In short, most job seekers in the sample in both countries were not alone in their job search: it is a process into which the extended family, and even those outside it, are drawn.

\section{Helping the Family Without Pay}

Perhaps the activity which takes up the most time of the educated unemployed youth is helping the family without pay. ${ }^{2}$ In Ghana, 77 per cent of the respondents said they depended mostly on their parents, and 14 per cent on other relatives, for their daily needs of food, shelter and clothing. This hardly needs emphasising in a kinshipconscious society like transitional Ghana. Older and working members of the family consider it an obligation to perform the welfare services needed for the survival of the group. Reciprocally, the unemployed youth (71 per cent of our sample) contributed to their own and the family's subsistence by offering free labour and services in such activities as farming, wood carving, cloth weaving, tailoring, carpentry or trading. At times, such assistance might be given to parents doing salaried work, as for example when a school leaver records the daily sales on behalf of his father who is employed in a government trading firm. Though such activities might take three hours a day (or more) for five days a week, there are no cash payments.

\footnotetext{
2 Evidence on this was scarcer in Sri Lanka.
}

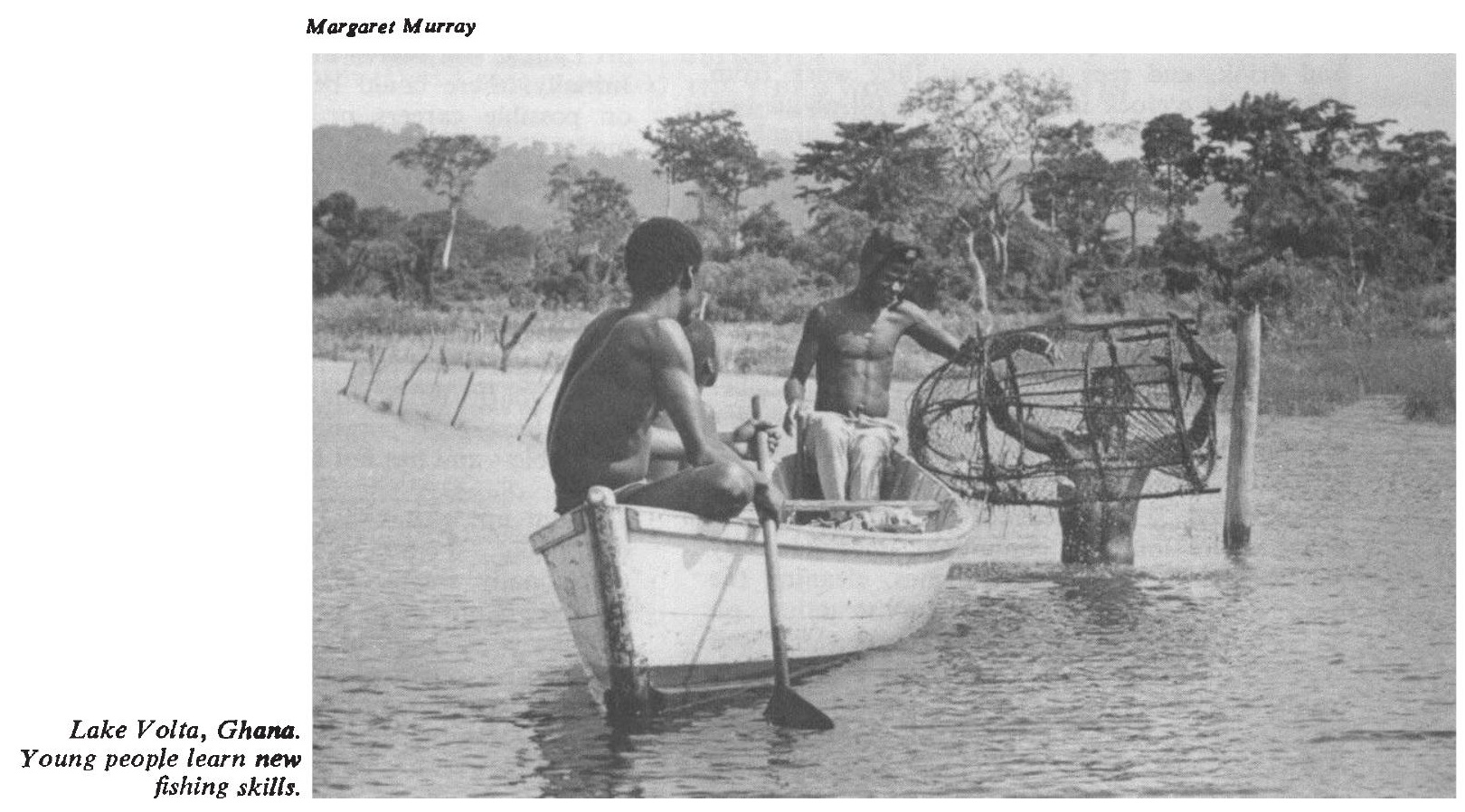


From this, we note that the unemployed youth are not necessarily idle. This is so especially among those who remain in the village. Nevertheless, those who migrate to urban areas also stay with relatives and perform similar duties, though perhaps less intensively. They may spend part of their time out of the house waiting at Employment Centres, but mostly they spend their time with families or relatives whose work allows occasional assistance.

\section{Using Time for Casual Labour}

The unemployed youth in Ghana earn incomes also through casual work. This usually refers to any activity for which payment (usually in the form of money) is made immediately or at a later date, but not regular (usually less than three occasions in a month, on average) or structured enough to be considered as employment. Respondents in our Ghana sample (again, there was less evidence of this from Sri Lanka) performed various forms of casual labour according to their locality and sex. For example, rural males in groups of four or five might weed cocoa farms just before the rainy season, plant cocoa seedlings or harvest cocoa pods. One major source of casual labour among the males is what is popularly called 'by day' - a day's assignment usually consisting of land clearing for the cultivation of crops. Here a farmer picks a number of boys, arranges the 'charge' with them (usually about half of the minimum daily wage for employees in the public sector), provides food and drink, and sees to it that they work from about eight o'clock in the morning till about two o'clock in the afternoon (with a lunch break of about one hour). Females are engaged in carrying (eg cocoa) and selling duties. Like their counterparts in the urban area, the rural females also casually sell manufactured foodstuff like bread at lorry stations and at market places. Urban males may go to factories, markets and construction sites to do packing and carrying duties. These instances cast doubt on the belief that educated unemployed youth refuse to engage in manual labour or 'soil their hands'.

Unemployed school leavers are known to be using their time for communal and voluntary activities such as digging trenches, cleaning the bush around the village or constructing pit latrines. Occasionally, they sit and watch self employed people in the 'informal sector'-tinsmith, automechanics, goldsmiths-and informally learn their crafts. They may organise sporting activities (such as football clubs) and, in urban areas, visit cinema houses if they can afford the entry fees. The academically ambitious ones may even use part of their time to study in order to improve their grades or to gain higher qualifications. But we lack sufficient data from our respondents to support or generalise the assertion.

\section{Implication for Development Policy and Thinking}

The foregoing discussion on how educated unemployed youth use their time highlights options for consideration in development policy and thinking, although social attitudes may not permit the same policies in Ghana and Sri Lanka.

First, the fact that the youth are unemployed does not necessarily imply that they are idle. They are willing to, and do, participate in economic activities, however irregular or small the amount of time or work may be. The need is for full time work on a regular basis. Perhaps the policy option here could be adjustment to available occupational opportunities such as self employment for which more than a third of the females in both countries and the males in Ghana, in our sample, expressed strong interest. Moreover, the fact that four out of every five youths seeking salaried employment in Ghana will eventually end up in self employment adds weight to this recommendation for that country.

A related policy option is better occupational information. One wonders why the youth in these saturated modern sector environments, especially Sri Lanka, still search and hope for salaried jobs. Initially, there could be participatory discussion on possible careers or occupations outside the modern sector, backed by practical measures such as narrowing income differentials and conditions of service in modern sector jobs, and/or rewarding self employed labour through good prices for agricultural produce. Thirdly, the fact that most of the educated youth depended on and worked with their families indicates that programmes for utilising the talents and the time of the youth should not focus solely on the youth themselves; incorporating the family might be profitable-and has not been tried.

To sum up: although the educated unemployed do make themselves useful and do earn occasionally, their contribution is essentially 'surplus to requirements'; room is made for them and use is made of them, but is dispensed with at the earliest opportunity, so that it may in net terms be a drain, not a contribution. What they and their families need is help in identifying and developing avenues of opportunity in their localities. This might involve, especially in Sri Lanka, 
adjustments in their hopes and social values. It would certainly demand imaginative approaches from governments and other agencies concerned for the better deployment of educated youth.

\section{References}

Boakye, J. K. A., Job Seekers and Job Placement Services in Ghana, IDS/CDS, forthcoming

Dore, R. P. et al, 1975, 'Qualification and Selection in Educational Systems: a Programme of Research, Part 1', Discussion Paper 70, IDS, Sussex

Foster, P., 1965, Education and Social Change in Ghana, Routledge and Kegan Paul
Ghana, Republic of, 1975, Pattern of Employment and Employment Prospects of Polytechnic Graduates in Ghana, Ministry of Economic Planning, Manpower Division

-1977, Five Year Development Plan, 1975/76$1979 / 80$

International Labour Organisation, 1971, Matching Employment Opportunities and Expectations: a Programme of Action for Ceylon, Report

Mook, B. T., nd, 'Job Seekers in Sri Lanka', mimeo

Oxenham, J. C. P., Job Seekers and Job Placement Services in Sri Lanka, forthcoming 